\section{Case Reports in Neurology}

\title{
Cerebral Autosomal Dominant Arteriopathy with Subcortical Infarcts and Leukoencephalopathy (CADASIL) - Still to be Considered in the Presence of Vascular Risk Factors
}

\author{
Dinesh Naidu Ganesan ${ }^{a} \quad$ Thibault Coste $^{\text {b, c }}$ \\ Narayanaswamy Venketasubramanian ${ }^{d}$ \\ aNational University of Ireland Galway, Galway, Ireland; bUniversité de Paris, UMR-S1141, \\ Paris, France; 'Service de Génétique Moléculaire Neurovasculaire, Hôpital Lariboisière, \\ Paris, France; dRaffles Neuroscience Centre, Raffles Hospital, Singapore, Singapore
}

\section{Keywords}

CADASIL $\cdot$ Risk factors $\cdot$ Magnetic resonance imaging $\cdot$ Skin biopsy $\cdot$ NOTCH3 gene

\begin{abstract}
Cerebral Autosomal Dominant Arteriopathy with Subcortical Infarcts and Leukoencephalopathy (CADASIL) is a rare hereditary vasculopathy that primarily affects the brain, caused mostly by missense mutations of the NOTCH3 gene which is located on chromosome 19. Clinically, it manifests as transient ischemic attacks and strokes in individuals under the age of 60 years without vascular risk factors. We report a 46 -year-old male with a 9 and 3-month history of progressive unilateral lower limb weakness and dysarthria, respectively. He had a history of diabetes mellitus but no hypertension, hyperlipidemia, or smoking history. Both parents had a stroke at the age of 65 years. Neurological examination was significant for moderate dysarthria and reduced right upper limb dexterity. Magnetic resonance imaging (MRI) of the brain revealed extensive white matter disease, lacunar infarcts, and a few microhemorrhages. Electron microscopy of his skin biopsy showed electron-dense deposits of extracellular osmiophilic granular material adjacent to smooth muscle cells. NOTCH3 gene analysis revealed a heterozygous typical mutation in exon 6 . He was commenced on aspirin and atorvastatin. Over time,
\end{abstract}

$\begin{array}{ll} & \text { N. Venketasubramanian } \\ \text { Raffles Neuroscience Centre, Raffles Hospital } & \\ & 585 \text { North Bridge Road } \\ & \text { \#09-00 Raffles Specialist Centre, Singapore } 188770 \text { (Singapore) } \\ \text { drnvramani@gmail.com }\end{array}$




\section{Case Reports in Neurology}

Case Rep Neurol 2020;12:196-201

DOI: $10.1159 / 000507542$

(c) 2020 The Author(s). Published by S. Karger AG, Basel www.karger.com/crn

Ganesan et al: Cerebral Autosomal Dominant Arteriopathy with Subcortical Infarcts and Leukoencephalopathy (CADASIL) - Still to be Considered in the Presence of Vascular Risk Factors

he became more dysarthric and demented. MRI revealed the progression of the white matter disease and a new right subcortical infarct. His aspirin was switched to clopidogrel, and donepezil was added. CADASIL should be considered among younger stroke patients with vascular risk factors, especially in the presence of widespread white matter disease. Genetic counselling may be needed after the diagnosis is made.

(C) 2020 The Author(s)

Published by S. Karger AG, Basel

\section{Introduction}

Cerebral autosomal dominant arteriopathy with subcortical infarcts and leukoencephalopathy (CADASIL) is a rare vascular disease with an autosomal dominant pattern of inheritance. It is due to NOTCH3 mutations located on chromosome 19 [1]. The underlying pathology involves the accumulation of abnormal transmembrane deposits on smooth muscle cells of blood vessels within the brain and other organs [2]. This impairs the functionality of these vessels, predisposing the patient to ischemic events that manifest as migraine with aura in some individuals. Other patients experience transient ischemic attacks or strokes that occur before the age of 60 years [3]. The recurrence of these ischemic events predispose patients to dementia and may eventually cause death [4].

The proposed criteria for the diagnosis of CADASIL include strokes or stroke-like episodes, a stepwise or progressive course, among younger individuals free of the classical vascular risk factors, with magnetic resonance imaging (MRI) of the brain showing a diffuse leukoencephalopathy with subcortical infarcts in the basal ganglia and white matter [5]. However, a report from Japan showed that $65 \%$ of their CADASIL cases confirmed by molecular tests had vascular risk factors [6]. We report a case of a patient presenting with stroke and extensive white matter disease on brain MRI, with a history of diabetes mellitus that was shown to be due to CADASIL.

\section{Case Report and Case Presentation}

A 46-year-old right-handed male presented with a 9-month history of progressive right lower limb weakness and a 3-month history of progressive unclear speech. Of note, his medical history included diabetes mellitus for which he was on metformin and linagliptin, but no hypertension, hyperlipidemia, coronary artery disease, peripheral arterial disease, or smoking. He had no history of headaches. His family history is significant with his hypertensive mother having a stroke at the age of 65 years, his father having a stroke at a similar age.

On examination, the patient appeared healthy. His blood pressure was 110/70 $\mathrm{mm} \mathrm{Hg}$. Heart rate was 80 beats per minute and regular. No aphasia, anopia, or neglect was observed. Eye, face, palate, and tongue movements were normal although mild dysarthria was noted. Bilateral limb tone, power, reflexes, and coordination were normal, but he had reduced right upper limb dexterity. All sensory modalities were normal. On auscultation, neither cervical nor ocular bruits was found. Cardiac examination was normal.

Brain MRI showed extensive white matter disease within the subcortical regions including the anterior temporal pole, and multiple lacunar infarcts (Fig. 1). Gradient echo MRI images showed microhemorrhages. Ultrasonography of his extracranial and intracranial arteries was normal.

\section{Karger'=}




\section{Case Reports in Neurology}

Case Rep Neurol 2020;12:196-201 DOI: $10.1159 / 000507542$

(c) 2020 The Author(s). Published by S. Karger AG, Basel www.karger.com/crn

Ganesan et al: Cerebral Autosomal Dominant Arteriopathy with Subcortical Infarcts and Leukoencephalopathy (CADASIL) - Still to be Considered in the Presence of Vascular Risk Factors

Full blood count was normal. Random blood glucose was $7.5 \mathrm{mmol} / \mathrm{L}$. HbA1c was $7.3 \%$. LDL-cholesterol was $2.69 \mathrm{mmol} / \mathrm{L}$. Electrocardiogram and echocardiography were normal. Twenty-four-hour Holter monitor detected a short run of sinus tachycardia.

Despite the history of diabetes mellitus, the extensive white matter disease seen on brain MRI prompted a possible diagnosis of CADASIL.

A skin biopsy showed electron-dense deposits of extracellular osmiophilic granular material adjacent to smooth muscle cells, consistent with the diagnosis of CADASIL (Fig. 2).

Molecular genetic test revealed a heterozygous mutation in exon 6 of the NOTCH3 gene (NM_000435.2:c.994C>T), leading to a replacement of an arginine by a cysteine residue at position 332 p.(Arg332Cys). This mutation located in EGF8 is typical of CADASIL.

He was commenced on aspirin and atorvastatin. Over time, he became more dysarthric. Brain MRI revealed the progression of the white matter disease and a new right subcortical infarct. Aspirin was switched to clopidogrel. The patient was subsequently noted by his wife to become more forgetful, with inability to manage his medications and financial affairs. His Mini-Mental State Examination score was 13/30, indicative of dementia. He was thus started on donepezil. His vascular risk factors are under control: latest HbA1c is 6.5\%, LDL-cholesterol $1.53 \mathrm{mmol} / \mathrm{L}$.

\section{Discussion and Conclusion}

Clinical features of CADASIL include migraine with aura, ischemic stroke-like events, cognitive disturbances, and mood changes. The most common initial complaint for patients with CADASIL in their 30s is migraine with aura [7]. Migraine with aura is generally followed by ischemic stroke-like events, which accounts for approximately $85 \%$ of the patients [8]. These tend to occur in patients at ages between 30 and 60 years and generally involve motor symptoms, ataxia, and dysarthria but may also be purely sensory.

Clinically, our patient did not experience any migraines with aura or behavioral changes. The existence of motor symptoms in the form of his progressive right lower limb weakness dysarthria and reduced right upper limb dexterity can be attributed to multiple ischemic stroke-like events, which he may have experienced in the past. This illustrates the vascular nature of his disease.

Cognitive decline in most cases is stepwise in nature, too [9]. It occurs early in patients with CADASIL, 50\% of whom have some form of cognitive decline by the age of 45 years [10]. Our patient developed dementia later in the course of his illness, after a few incident symptomatic strokes.

Mood disturbances occur in approximately a quarter of the patients [11]. These include but are not limited to moderate and major depression. These symptoms were absent in our patient.

Imaging modalities such as MRI may be used to visualize ischemic regions within the brain. These are typically described as well-circumscribed lacunes, which are hyper- or hypointensities within the subcortical regions and basal ganglia, together with diffuse and extensive subcortical white matter disease [12]. Brain MRI of our patient showed the presence of these features, extending into the anterior temporal pole. It also subsequently showed the presence of a new right subcortical infarct. Cerebral microhemorrhages frequently occur in the context of vascular disease. These occur in 31-69\% of the patients with CADASIL and are

\section{Karger'=}




\section{Case Reports in Neurology}

Case Rep Neurol 2020;12:196-201 DOI: $10.1159 / 000507542$

(c) 2020 The Author(s). Published by S. Karger AG, Basel www.karger.com/crn

Ganesan et al: Cerebral Autosomal Dominant Arteriopathy with Subcortical Infarcts and Leukoencephalopathy (CADASIL) - Still to be Considered in the Presence of Vascular Risk Factors

an indicator that the disease has progressed to the advanced stage [13]. These were also present on the brain MRI of our patient.

Additional tests to aid the diagnosis of CADASIL include genetic testing and skin biopsies. Genetic testing involves the retrieval of a small amount of venous blood, which is tested for the presence of a NOTCH3 mutation, which are found in all patients afflicted by the disease [14]. It is the gold standard for the diagnosis of CADASIL. Molecular screening also allows the clinician to check other genes involved in small vessel diseases. Although highly sensitive, genetic testing can be relatively expensive. In this instance, a skin test can be performed instead. These skin biopsies in individuals with CADASIL, which are typically obtained from clinically normal skin, will show multiple granular electron-dense deposits within the cell membranes of vascular smooth muscle cells. It has been reported to be as accurate as genetic testing and can be used as first-line in view of its lower cost [15]. Skin testing was performed on our patient and yielded a positive result. This was confirmed by the gene test for a NOTCH3 genetic mutation.

With regards to the management of the patient, risk factors for stroke should be addressed in the form of medication and lifestyle modification where appropriate, although treatment remains largely unproven. As for antithrombotic therapy, there is no evidence to suggest benefit from antiplatelet or anticoagulant therapy. We screen the patient at every visit for hypertension.

In view of the autosomal dominant nature of the disease, genetic counselling is crucial. The patient and his wife have been counselled about the hereditary nature of CADASIL and how genetic screening may be important for their offspring.

\section{Conclusion}

CADASIL is a rare condition that should be suspected in the context of younger patients who present with stroke-like episodes in both the presence and absence of classical vascular risk factors with brain MRI showing diffuse leukoencephalopathy with subcortical infarcts. Diagnosis is multifaceted and may involve obtaining brain MRI images, skin biopsies, and performing genetic testing. There is no established treatment for the diseases, and management is supportive. More research and funding will have to be devoted in order to treat this condition.

\section{Statement of Ethics}

This research complies with the guidelines for human studies and was conducted ethically in accordance with the World Medical Association Declaration of Helsinki. The patient gave his informed consent to publish this case report.

\section{Conflict of Interest Statement}

There were no conflicts of interest in writing this case report.

\section{Karger'}




\section{Case Reports in Neurology}

\section{Funding Sources}

No funding was received for this case report.

\section{Author Contributions}

D.N.G. performed the literature search and prepared the drafts of the manuscript. T.C. performed the genetic test and critically reviewed the manuscript. N.V. was involved in supervising the first author, preparing and revising the manuscript.

\section{References}

1 Joutel A, Corpechot C, Ducros A, Vahedi K, Chabriat H, Mouton P, et al. Notch3 mutations in CADASIL, a hereditary adult-onset condition causing stroke and dementia. Nature. 1996 Oct;383(6602):707-10.

2 Ruchoux MM, Maurage CA. CADASIL: cerebral autosomal dominant arteriopathy with subcortical infarcts and leukoencephalopathy. J Neuropathol Exp Neurol. 1997 Sep;56(9):947-64.

3 Chabriat H, Joutel A, Dichgans M, Tournier-Lasserve E, Bousser MG. Cadasil. Lancet Neurol. 2009 Jul;8(7):643-53.

4 Chabriat H, Hervé D, Duering M, Godin O, Jouvent E, Opherk C, et al. Predictors of Clinical Worsening in Cerebral Autosomal Dominant Arteriopathy With Subcortical Infarcts and Leukoencephalopathy: Prospective Cohort Study. Stroke. 2016 Jan;47(1):4-11.

5 Davous P. CADASIL: a review with proposed diagnostic criteria. Eur J Neurol. 1998 May;5(3):219-33.

6 Mizuta I, Watanabe-Hosomi A, Koizumi T, Mukai M, Hamano A, Tomii Y, et al. New diagnostic criteria for cerebral autosomal dominant arteriopathy with subcortical infarcts and leukocencephalopathy in Japan. J Neurol Sci. 2017 Oct;381:62-7.

7 Vahedi K, Chabriat H, Levy C, Joutel A, Tournier-Lasserve E, Bousser MG. Migraine with aura and brain magnetic resonance imaging abnormalities in patients with CADASIL. Arch Neurol. 2004 Aug;61(8):123740.

8 Dichgans M, Mayer M, Uttner I, Brüning R, Müller-Höcker J, Rungger G, et al. The phenotypic spectrum of CADASIL: clinical findings in 102 cases. Ann Neurol. 1998 Nov;44(5):731-9.

9 Peters N, Herzog J, Opherk C, Dichgans M. A two-year clinical follow-up study in 80 CADASIL subjects: progression patterns and implications for clinical trials. Stroke. 2004 Jul;35(7):1603-8.

10 Dichgans M, Filippi M, Brüning R, Iannucci G, Berchtenbreiter C, Minicucci L, et al. Quantitative MRI in CADASIL: correlation with disability and cognitive performance. Neurology. 1999 Apr;52(7):1361-7.

11 Valenti R, Poggesi A, Pescini F, Inzitari D, Pantoni L. Psychiatric disturbances in CADASIL: a brief review. Acta Neurol Scand. 2008 Nov;118(5):291-5.

12 Auer DP, Pütz B, Gössl C, Elbel G, Gasser T, Dichgans M. Differential lesion patterns in CADASIL and sporadic subcortical arteriosclerotic encephalopathy: MR imaging study with statistical parametric group comparison. Radiology. $2001 \mathrm{Feb}$;218(2):443-51.

13 Puy L, De Guio F, Godin O, Duering M, Dichgans M, Chabriat H, et al. Cerebral Microbleeds and the Risk of Incident Ischemic Stroke in CADASIL (Cerebral Autosomal Dominant Arteriopathy With Subcortical Infarcts and Leukoencephalopathy). Stroke. 2017 Oct;48(10):2699-703.

14 Di Donato I, Bianchi S, De Stefano N, Dichgans M, Dotti MT, Duering M, et al. Cerebral Autosomal Dominant Arteriopathy with Subcortical Infarcts and Leukoencephalopathy (CADASIL) as a model of small vessel disease: update on clinical, diagnostic, and management aspects. BMC Med. 2017 Feb;15(1):41.

15 Mayer M, Straube A, Bruening R, Uttner I, Pongratz D, Gasser T, et al. Muscle and skin biopsies are a sensitive diagnostic tool in the diagnosis of CADASIL. J Neurol. 1999 Jul;246(7):526-32. 
Case Reports in Neurology
Case Rep Neurol 2020;12:196-201

DOI: $10.1159 / 000507542$ (c) 2020 The Author(s).
www.karger.com/crn

Ganesan et al: Cerebral Autosomal Dominant Arteriopathy with Subcortical Infarcts and Leukoencephalopathy (CADASIL) - Still to be Considered in the Presence of Vascular Risk Factors

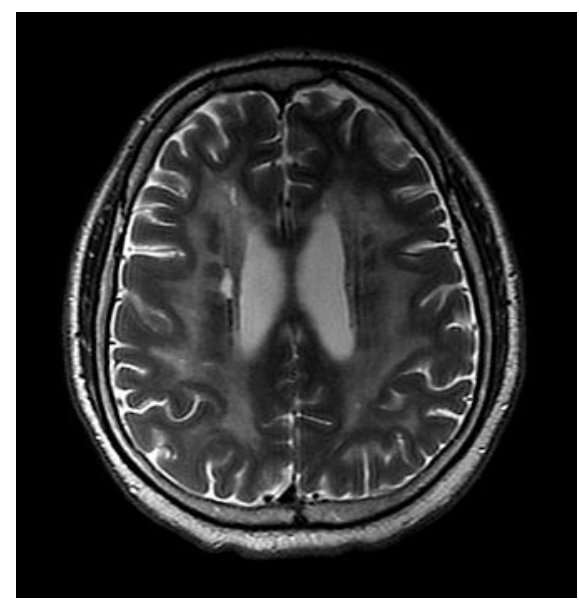

Fig. 1. T2-weighted brain MRI showing extensive white matter disease and lacunar infarcts.

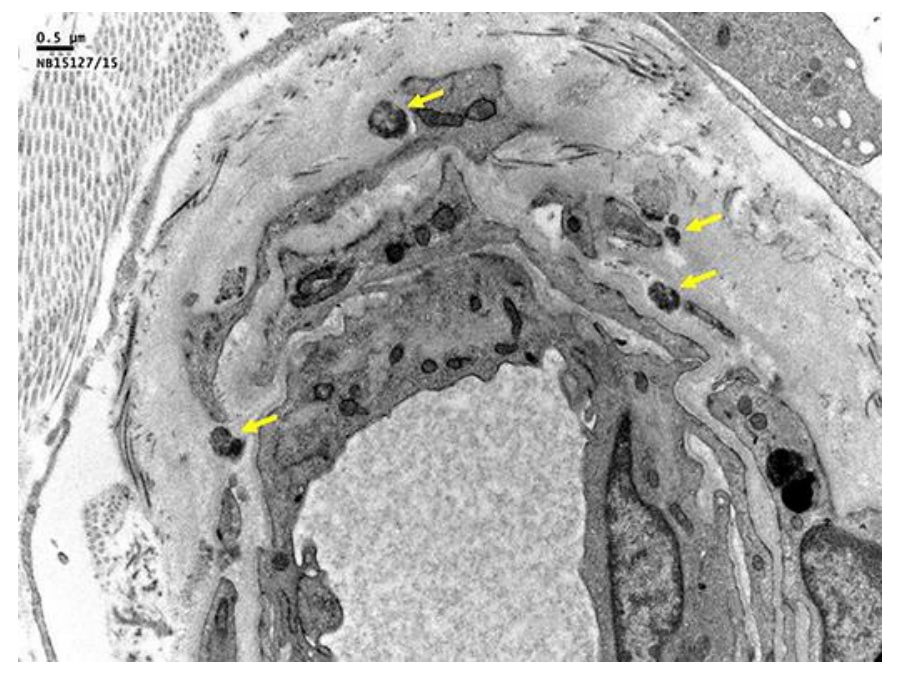

Fig. 2. EM photograph of skin biopsy showing multiple granular electron dense deposits (arrows) associated with pericytes and smooth muscle cells of the capillaries and arterioles in skin biopsy. 